American Journal of Pharmaceutical Education 2011; 75 (2) Article 39.

LEGACY ARTICLES

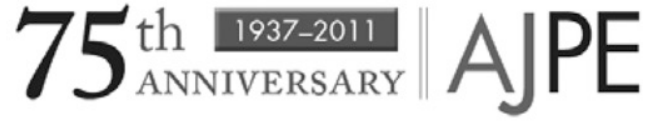

\title{
The Marihuana Menace
}

Marihuana is the Mexican name for the plant known as Indian hemp. Its botannical name is Cannabis sativa, Linne.

Indian hemp was originally grown in the New England, the Virginia and the Pennsylvania Colonies for fiber. From these colonies, its cultivation spread to the early settlements in Kentucky and Missouri. It has also been grown for commercial purposes at various times in Illinois, Indiana, Southeastern Pennsylvania, Nebraska, Iowa and California. In 1931, there were under cultivation for commercial purposes approximately 750 acres in Wisconsin, Illinois and Kentucky. At the present time, it grows wild in nearly every state of the Union, but most abundantly in Western Missouri, Iowa, Southern Minnesota, the Southwestern and Western states.

Today, the plant is grown primarily for its fiber, which is used in making fabrics, rope, etc.; for the fruit (hemp seed) which is used as a bird food and for the production of oil and oil cake; for the flower tops of the pistillate (female) plant which is used as a drug. When it is grown for fiber, it is harvested just before the male flowers begin to shed pollen. At this time, it is not sufficiently mature to be used as a drug because the maximum amount of active principle has not yet developed. When grown for the production of the drug, it is allowed to remain in the field several weeks longer but the male plants are removed because pollination destroys some of the active principle. When the plant is cultivated for the production of seed, it is allowed to remain in the field until the fruit is fully ripe.

The active principle of the plant resides in the resin which occurs in greatest amounts in the flower tops. This fact is evidently not known to the makers of marihuana cigarettes because all of those which I have examined consisted almost wholly of the crushed leaves and stems. Frorn this, it follows that the material which is commonly smoked cannot be very potent.

Hashish is a confection made by mixing the flower tops with sugar and aromatic spices. It is eaten by habitues in the Orient but, as far as I know, it is not used in this country. In the Oriental countries where the drug is smoked, the flower tops are used and they are usually smoked in a pipe. 
American Journal of Pharmaceutical Education 2011; 75 (2) Article 39.

Much of a sensational nature has been written in the popular literature about the effects of this drug. As a matter of fact, however, our knowledge of its psysiological action is rather indefinite because the effects are largely psychic and, therefore, they cannot be determined on experimental animals. Medical men and scientists have disagreed on its physiological properties and some are inclined to minimize its harmfulness but there is evidence to indicate that, when used excessively, its effect is deleterious. The principal effect of the drug is upon the brain which loses the power of directing and controlling thought. Its continuous use in large amounts no doubt produces mental deterioration in many cases. Its more immediate effect apparently is to remove the normal inhibitions of the individual and to release any anti-social tendencies which may be present. Those who indulge in its use habitually, eventually develop a delirious rage after its administration. During this time they are, temporarily at least, irresponsible and prone to commit violent crimes. The following excerpt from a report of one of the experts of the Sub-committee on Cannabis of the Opium Advisory Committee of the League of Nations gives some indication of the quantities which are consumed by individuals who become dangerous: "If hemp is consumed at very frequent intervals-some inveterate addicts smoke over fifty pipes of it in 24 hours-the subject lives in a state of permanent stupor interrupted by increasingly frequent periods of exaltation and well-being. These alternate with crises of melancholia accompanied by terrifying halucinations which provide confirmation of his or her more or less delirious convictions. At this stage, addicts become dangerous; they are intensely susceptible to suggestion; the simplest affirmation or the slightest obstacle arouses transports of fury, joy or jealousy or a menacing attitude. Eventually they have to be placed under restraint as the result of some crime or acts of violence." The experts also contend that the drug is not habit-forming. That is its use does not induce a bodily craving for the drug when withdrawn. Those who indulge in it do so solely for the pleasure or relief from worry which it is assumed to give them.

Up until a few years ago, the illegitimate use of the drug was observed particularly among the Latin-American or Spanish-speaking portions of our population. The sale of 
American Journal of Pharmaceutical Education 2011; 75 (2) Article 39.

cannabis cigarettes was confined principally to the states along the Mexican border, the cities of the Southwest and the seaports on the East and West Coasts. Apparently, its use has spread in recent years to other sections of the United States which may be due in part at least to the wide publicity which has been given to its effects by the press. However, it is believed that the extent of its use as stated in newspapers and other publications is greatly exaggerated. In 1936, for instance, there were only 15,715 cigarettes seized by law-enforcement officers in the entire United States. From time to time, unauthenticated reports are given out that marihuana cigarettes are being smoked by school children. So far as I know, in each instance where these reports have been investigated, they have been found to be untrue or only an isolated case or two hase been discovered.

The wide publicity given to the harmful effects which may be produced in those who indulge in the use of cannabis to satisfy their curiosity or a craving for a new experience has resulted in the passage of both, federal and state laws, to protect the weak and reckless. These laws forbid the cultivation of cannabis and its use for the satisfaction of curiosity or pleasure and restrict its cultivation and use for legitimate purposes, but neither the federal or state laws cover the plant which grows wild in such profusion that its eradication seems to be an impossibility.

On August 2, 1937, the Congress of the United States passed a law regulating the importation, manufacture, production, compounding, sale, dealing in, dispensing, prescribing, administering and giving away of marihuana. This law became effective on October 1, 1937. In general, it provides for the production, manufacture, distribution and use of cannabis under strict supervision which is attained through the imposition of taxes on all who are given the legal right to produce, manufacture, or distribute the plant or any of its parts. In addition, all of the 48 states and the Territory of Hawaii now have laws of some nature for the control of cannabis. Of these, 37 control or license production; 44 control possession; and all 48 control sale. Twenty-nine (29) states include control and regulation of cannabis in the uniform state narcotic act. Eleven (11) states have special cannabis laws and 8 include cannabis in the general narcotic laws. 
American Journal of Pharmaceutical Education 2011; 75 (2) Article 39.

Cannabis as a drug seems to have met the same fate as that meted out to the medicinal wines during the days of prohibition. The bad reputation given it because of its use for illegitimate purposes and the legal restrictions imposed on the physician and pharmacist have caused it to fall into almost complete desuetude as a medicine. Perhaps this is desirable from the standpoint of the welfare of the public but I am skeptical about the benefits which may accrue. I doubt if we can build up the race by protecting the weak.

Andrew G. DuMez. 